\title{
First record of the genus Rutylapa from China, with description of a new species (Diptera: Keroplatidae)
}

\author{
Jian Cao, Zuji Zhou, Huachao Xu, Hong Wu, Yiping Wang \& Mei Wang
}

Cao, J., Zhou, Z., Xu, H., Wu, H., Wang, Y. \& Wang, M. 2009: First record of the genus Rutylapa from China, with description of a new species (Diptera: Keroplatidae). — Entomol. Fennica 20: 179-181.

This is the first report of the genus Rutylapa Edwards, 1929, from China. Rutylapa longa Cao \& Xu sp. n. is described and figured, and it is compared to the other Palaearctic species of the genus, $R$. ruficornis Zetterstedt.

J. Cao, Provincial Key Laboratory of Forest Protection, Sichuan Agricultural University, Ya'an, Sichuan 625014, P. R. China, and Changdu Secondary Vocational and Technical School, Changdu, Tibet 854000, P. R. China; E-mail: caojian0818@yahoo.com.cn

Z. Zhou, Provincial Key Laboratory of Forest Protection, Sichuan Agricultural University, Ya'an, Sichuan 625014, P. R. China; E-mail: zujizhou@yahoo. com.cn

H. Xu, H. Wu \& Y. Wang, School of Forestry and Biotechnology, Zhejiang Forestry College, Lin'an, Zhejiang 311300, P. R. China; E-mail: xhcinsect@zjfc. edu.cn,wh931908@sohu.com,yp@zjfc.edu.cn

M. Wang, Nanchong Institute of Agricultural Sciences, Nanchong, Sichuan 637000, P. R. China; E-mail: wangmei2529@163.com

Received 11 February 2007, accepted 5 February 2009

\section{Introduction}

Rutylapa Edwards, 1929, is a rather small group in the tribe Orfeliini of the Keroplatinae, represented by about 17 species (not including the species dealt with here) found in the world (Evenhuis 2006). Of these, most of the species are known from the Afrotropical Region and the Australasian Region. Only one species is known from the Palaearctic Region and four species from the Oriental Region.

This is the first report of the genus Rutylapa from southwest China, as a new species among the specimens deposited in the entomological collection of Zhejiang Forestry College, Lin'an, Zhejiang, P. R. China (ZJFC) was discovered. Undoubtedly, this is a significant addition to the knowledge of the genus Rutylapa in Southeast Asia.

The genus Rutylapa is distinguished from other related genera by the following characters (Edwards 1929, Søli et al. 2000): branches of M and $\mathrm{CuA}$ bare dorsally; posterior margin of anterior spiracle with erect black hairs; laterotergite bare; tibial setae in even rows on entire length of tibia; anterior spur of mid and hind tibia present but minute; vein A1 almost reaching wing margin.

\section{Material and methods}

Specimens were collected by sweeping and preserved in $80 \%$ alcohol. Holotype and paratype of 
the new species are deposited in ZJFC. Morphological terminology used follows that of Søli et al. (2000).

\section{Description of Rutylapa longa Cao \& Xu, sp. n. (Fig. 1)}

Material studied. Holotype $\widehat{\sigma}$ (ZJFC 060188) and paratype $\delta$. China, Sichuan province, Wolong National Natural Reserve, 21.VII.2006, Jian Cao.

Description. Male. Lengths: Body: $6.0 \mathrm{~mm}$; wing: $5.1 \mathrm{~mm}$.

Head. Vertex and occiput yellowish brown with fairly dense small black recumbent hairs. Three ocelli, median ocellus very small. Frons yellowish brown, bare. Antennae: scape and pedicel yellow. Flagellum: 14 segments, each with a few long setae; segment I dark brown with yellow basally, other dark brown, terminal segment tapered (Fig. 1a). Face dark brown with pale yellow laterally. Palpus: palpomere I obscurely yellow, palpomere II brown, palpomere III pale brown, palpomere IV pale yellow, long and slender.

Thorax. Mesonotum yellowish brown, uniformly setose; patch of thick black setae above wing root. Scutellum yellow, with a row of long dark setae on posterior margin. Anepisternum and laterotergite obscurely yellow, bare; katepisternum pale yellow, bare; mediotergite yellow with brown above, with a few short black setae apically. Halter pale yellow, knob pale brown.

Legs. Yellow. Tibiae with few setae and tibial setulae forming distinct regular rows throughout. Fore tibia without comb, mid tibia with only black posterior comb, hind tibia with black anterior and posterior combs. Tibial spurs black, fore and mid tibial spurs minute, shorter than thickness of tibial apex; anterior spur of hind tibia very minute, less than one-fifth of the posterior, posterior spur of hind tibia well developed, 2-2.5 times as long as the thickness of hind apex. Fore basitarsus 1.2 times as long as length of fore tibia, hind and mid basitarsi $0.8-0.9$ times as long as length of respective tibiae.

Wing (Fig. 1b). Hyaline with a pale brown spot subapically from costa to apex of cell $\mathrm{m} 2$ and a little pale spot around $\mathrm{CuA} 2$ subapically. Veins yellowish brown. Costa reaching one-third dis- tance from $\mathrm{R} 5$ to $\mathrm{M} 1$; Sc ends in $\mathrm{C}$ reaching the level of mid of Rs; Sc2 situated at level of basal $0.1-0.2$ between $\mathrm{h}$ and tip of Sc. Distance between tips of R1 and R4 1.8-2.0 times as long as R4. Ratio of radiomedial fusion / petiole of $\mathrm{M}$ : 2.0-2.4. Petiole of $\mathrm{M}$ one-fifth as long as length of M1. Veins M2 and A1 not reaching wing margin.

Abdomen. Tergite I obscurely yellow; tergites II-IV yellow with little irregular brown spot posterolaterally; tergite $\mathrm{V}$ dark brown with yellow triangular spot basally; tergite VI dark brown. Sternite I obscurely yellow with little dark brown spot apically; Sternite II dark brown with yellow medially; sternites III-IV yellow with dark brown triangular spot posteromedially; sternites V-VI dark brown.

Hypopygium (Fig. 1c-e). Yellow, rotated $180^{\circ}$. Tergite IX tapered from base to apex and subequal in length to gonocoxite. Cercus visible in dorsal view, subtriangular; hypoproct elongated, about 2.0 times as long as cercus. Gonocoxite broad, with black stout setae medially and dense fine setae laterally. Gonostylus consisting of two lobes; inner lobe slightly bending outward apically, short, with dense black stiff setae on apical half; outer lobe slightly bending downward and tapered apically, 2.0 times as long as inner lobe, with black stiff setae anteroventrally.

Female. Unknown.

Etymology. The species epithet derives from the Latin longus = long, referring to the long hypoproct.

Diagnosis. Rutylapa longa is similar to the other Palaearctic species of the genus, $R$. ruficornis Zetterstedt, 1851 (see Edwards 1913), but the new species is easily distinguished by the shape of its terminalia, e.g. hypoproct elongated, about 2.0 times as long as cercus, while in $R$. ruficornis hypoproct is short and indistinct. Tergite IX appears more elongated and tapered on the apical half in $R$. longa, and the pair of lobes on the apical margin of the gonocoxites are much smaller and with a short and narrow median emargination, while in $R$. ruficornis these lobes are broadly rounded and with a wide medial emargination.

Acknowledgements. We wish to express our thanks to Dr. Neal Evenhuis and Mr. Peter Chandler, for providing some related data. 

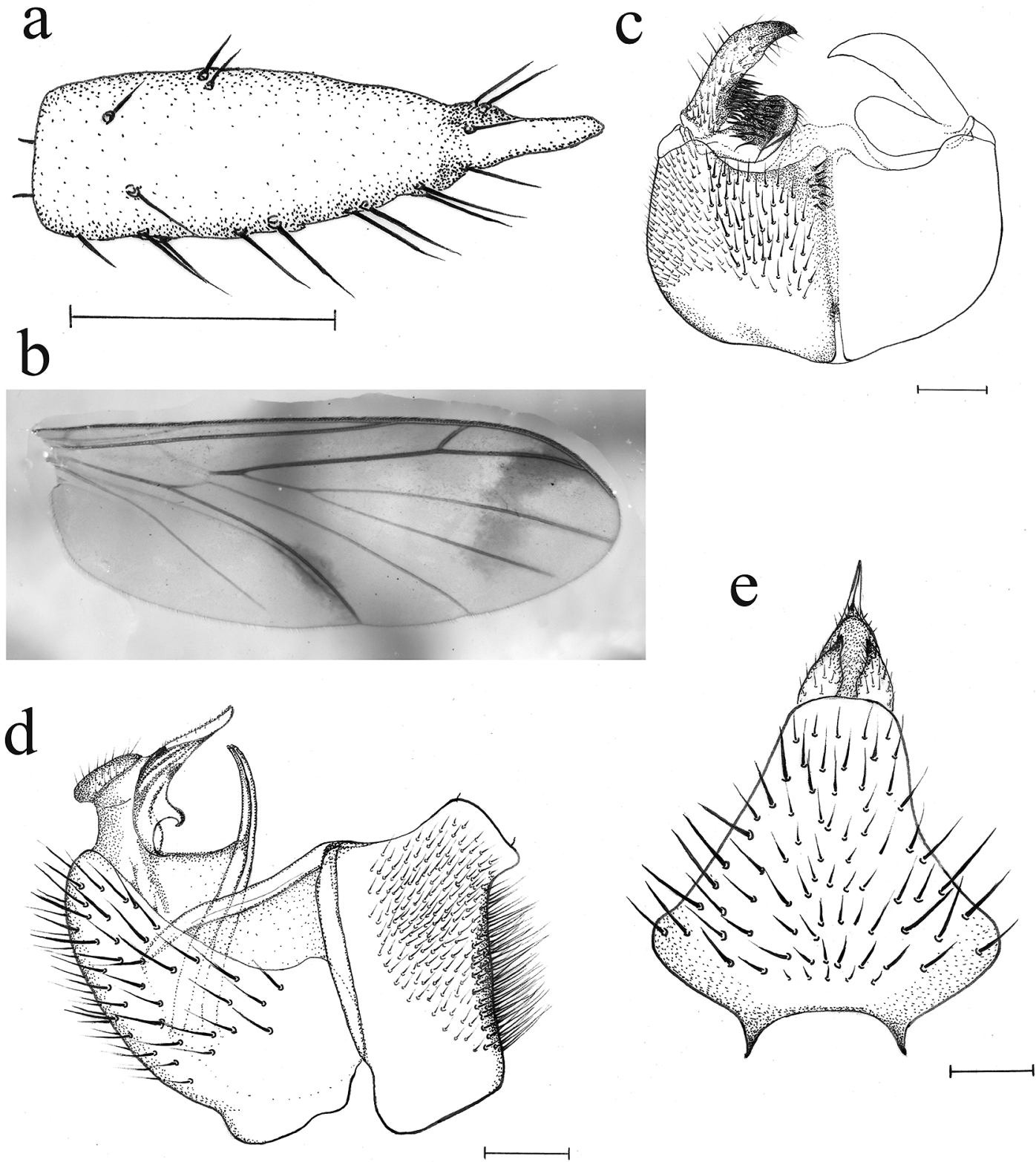

Fig. 1. Rutylapa longa Cao \& Xu sp. n. - a. Terminal flagellum. - b. Wing. - c. Male terminalia, ventral view (tergite IX and cercus omitted). - d. Male terminalia, lateral view (gonostyli omitted). - e. Male tergite IX and cercus, dorsal view. Scale bar $=0.1 \mathrm{~mm}$.

\section{References}

Edwards, F. W. 1913: Notes on British Mycetophilidae. Transactions of the Entomological Society of London: 334-382.

Edwards, F. W. 1929: Notes on the Ceroplatinae, with descriptions of new Australian species (Diptera, Mycetophilidae). - Proceedings of the Linnean Society of New South Wales 54(3): 162-175.
Evenhuis, N. L. 2006: Catalog of Keroplatidae of the world. - Bishop Museum Bulletin in Entomology 13: 1-178.

Søli. G. E., Vockeroth, J. R. \& Matile, L. 2000: 4. Families of Sciaroidea. - In: Papp, L. \& Darvas, B. (eds.), Contributions to a Manual of Palaearctic Diptera (with Special Reference to Flies of Economic Importance). Appendix 49-92. Science Herald, Budapest. 